\title{
Das trockene Auge: Neue Ansätze für Diagnostik und Therapie
}

\author{
Mostafa Heidari $^{a, b}$ Farsad Noorizadeh ${ }^{a}$ Kevin Wu ${ }^{c, d}$ Takenori Inomata ${ }^{e, f}$ \\ Alireza Mashaghig, h, i
}

${ }^{a}$ Basir Eye Health Research Center, Teheran, Iran;

${ }^{b}$ Farabi Eye Hospital, Department of Ophthalmology and Eye Research Center, Tehran University of Medical Sciences, Teheran, Iran; 'Department of Ophthalmology, Icahn School of Medicine at Mount Sinai, Ophthalmic Consultation Service, New York, NY, USA;

${ }^{d}$ New York Eye and Ear Infirmary of Mount Sinai, New York, NY, USA;

e Department of Ophthalmology, Juntendo University Faculty of Medicine, Tokio, Japan;

fDepartment of Strategic Operating Room Management and Improvement, Juntendo University Faculty of Medicine, Tokio, Japan;

'Systems Biomedicine and Pharmacology Division, Leiden Academic Centre for Drug Research, Leiden University, Leiden, Niederlande,

hDepartment of Chemistry and Chemical Biology, Harvard University, Cambridge, MA, USA;

'Department of Ophthalmology, Shanghai Medical College, Fudan University, Shanghai, China

\author{
Schlüsselwörter \\ Trockenes Auge · Immunmetabolismus · Mikrobiom · Omik · \\ Eye-on-a-Chip · klinische Zeichen · DES-Behandlung
}

\section{Zusammenfassung}

Das Trockene Auge (dry eye syndrome, DES) gehört zu den häufigsten Augenkrankheiten und betrifft Millionen von Menschen weltweit. Die Erkrankung ist jedoch noch nicht vollständig erforscht und bleibt nicht vollumfänglich behandelt. Multidisziplinäre Ansätze, darunter immunmetabolische Untersuchungen, Mikrobiomanalysen und biotechnologische Verfahren, haben wertvolle

Erkenntnisse erbracht. Darüber hinaus waren in der jüngeren Vergangenheit neue Entwicklungen bei den Ansätzen zur klinischen Beurteilung und den Behandlungsstrategien zu beobachten. Die vorliegende Arbeit gibt einen Überblick über die neuen Frontlinien in der Pathobiologie und Behandlung des Trockenen Auges.

(c) 2019 The Authors

\section{Einführung}

Das Trockene Auge (dry eye syndrome, DES) ist eine multifaktorielle Erkrankung der Augenoberfläche [1]. Aufgrund der hohen Prävalenz [2, 3] mit Millionen Betroffenen, die eine augenärztliche Behandlung suchen [4], stellt die Krankheit eine große Belastung für die Gesundheitsversorgung dar. Sie ist durch ein Trockenheits- und Fremdkörpergefühl oder Brennen sowie heftiges Augentränen und Lichtempfindlichkeit gekennzeichnet [5] und beeinträchtigt das klare Sehen sowie die Lebensqualität. Verschiedene Faktoren wie Trockenheit, Verletzung, Luftverschmutzung und Rauch, Allergene, Dysbiose und UV-Licht können die
Osmolarität der Tränenflüssigkeit erhöhen und den Tränenfilm destabilisieren, wodurch es zu einer sensorischen Stimulation und Reizung der Augenoberfläche kommt [6]. Dieser Prozess löst Entzündungsmechanismen aus, die zu einer Rekrutierung von Immunzellen und zu einer Überexpression von Zytokinen an der Augenoberfläche führen. Dadurch entsteht ein Teufelskreis, der den betroffenen Bereich weiter schädigt. Im Jahr 2017 veröffentlichte die «Tear Film and Ocular Surface Society» (TFOS) einen Bericht zum internationalen Dry Eye Workshop II (DEWS II), demzufolge das Trockene Auge in zwei Hauptformen eingeteilt wird: die hyposekretorische (mangelnde Tränenproduktion) und die evaporative Form. Erstere kann wiederum in zwei Unterklas- information@karger.com www.karger.com/kop

\section{(๑) 2020 S. Karger GmbH, Freiburg}

Karger ${ }^{\prime \prime}=$
Takenori Inomata

Department of Ophthalmology

Jutendo University Faculty of Medicine

Tokio, Japan

tinoma@juntendo.ac.jp 
Abb. 1. Beim Trockenen Auge kommt es durch eine oxidative Stoffwechsellage und Veränderungen des normalen Mikrobioms zu einer Entzündung auf der Augenoberfläche. Reaktive Sauerstoffspezies erhöhen die Instabilität des Tränenfilms und die Osmolarität und bewirken dadurch eine direkte oder indirekte Aktivierung des NLRP3Inflammasoms. Die beim Trockenen Auge auftretenden Veränderungen des Mikrobioms sind wiederum mit einem veränderten metabolischen Profil der Augenoberfläche verbunden, wodurch das Gleichgewicht zwischen pro- und anti-inflammatorischem Arm der Immunantwort in Richtung der proinflammatorischen Signalwege verschoben wird. Die induzierte Entzündung ist vermutlich das zentrale Element bei den Krankheitserscheinungen des Trockenen Auges. Abkürzungen: FoxO3: Forkhead box O3; LPS: Lipopolysaccharid; MnSOD: Mangan-Superoxid-Dismutase; NLRP3: NLR family pyrin-domain-containing 3; ROS: reactive oxygen species (reaktive Sauerstoffspezies); Sirt1: Sirtuin 1; SOD: Superoxid-Dismutase; Treg: regulatorische T-Zelle.

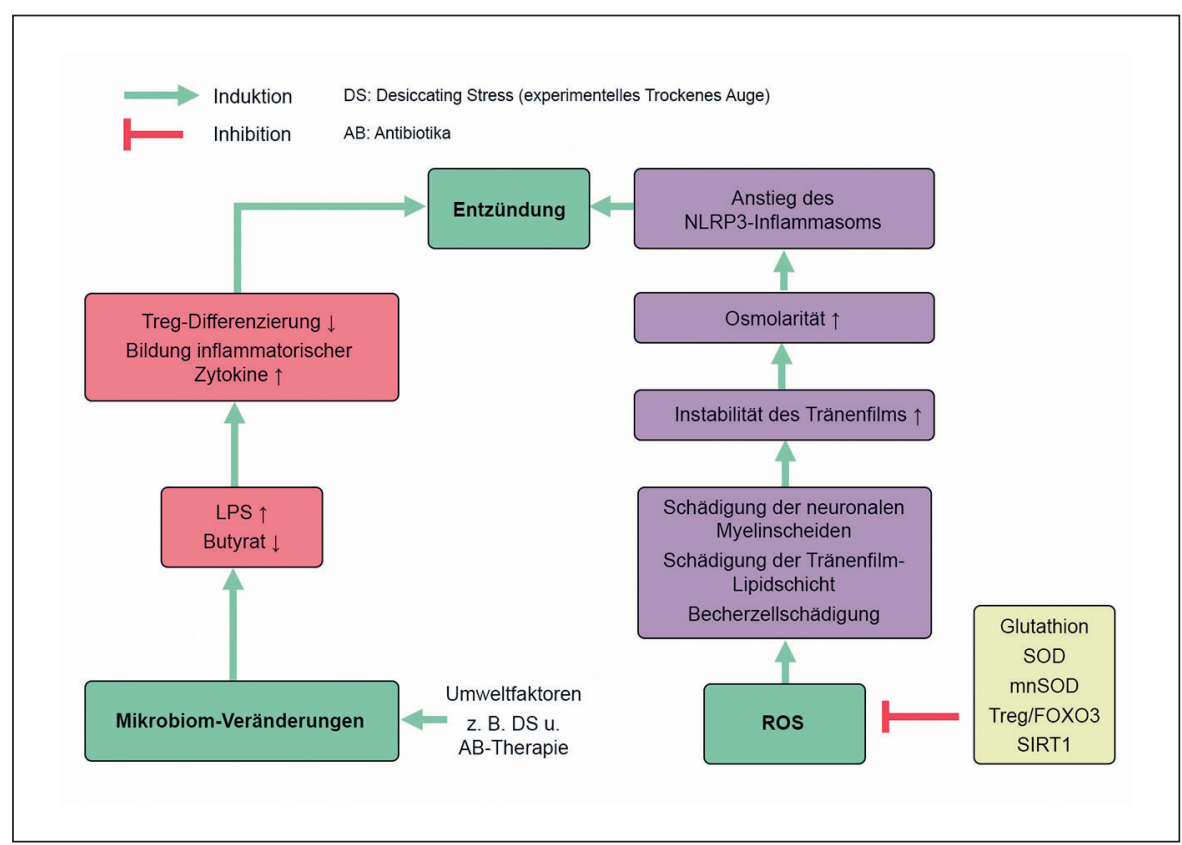

sen eingeteilt werden: das Trockene Auge bei Sjögren-Syndrom (SSDES) und das Nicht-Sjögren-Syndrom-assoziierte Trockene Auge (NSSDES) [7].

Trotz einiger Fortschritte ist das Trockene Auge noch immer nicht vollständig erforscht und behandelt. Es werden zunehmend interdisziplinäre Ansätze verfolgt, um die komplexen Zusammenhänge beim Trockenen Auge zu klären und neue Diagnose- und Behandlungsstrategien zu entwickeln. Neue Konzepte und Instrumente aus der analytischen Chemie, der Technologie, der Immunologie und der Mikrobiologie werden eingesetzt und in Hinblick auf die Behandlung des Trockenen Auges geprüft. In der vorliegenden Arbeit geben wir einen Überblick über die Entwicklungen in der Behandlung und Versorgung des Trockenen Auges in den vergangenen fünf Jahren. Dabei liegt der Schwerpunkt auf neu aufkommenden Konzepten und interdisziplinären Ansätzen, die dieses Gebiet möglicherweise in Zukunft wesentlich beeinflussen.

\section{Neue Erkenntnisse zur Pathogenese des Trockenen Auges}

In den vergangenen Jahren ist eine neue Forschungsfront an der Schnittstelle von Immunologie und Stoffwechselforschung entstanden. Das Gebiet des «Immunmetabolismus» hat bereits eine beträchtliche Anzahl von Entdeckungen hervorgebracht und zur Erforschung der Krankheit beigetragen [8]. Insbesondere konnten durch immunmetabolische Untersuchungen Einblicke in Autoimmunerkrankungen, einschließlich rheumatoider Arthritis [9] und Lupus erythematodes [10], gewonnen werden. Derzeit zeichnet sich ein empfindliches Wechselspiel zwischen metabolischer Reprogrammierung und Immunsignalwegen ab, was unser Verständnis der Entzündungsprozesse um eine zusätzliche Dimension erweitert $[11,12]$.

Das Gebiet des Immunmetabolismus ist neu in der Augenheilkunde. In anderen Bereichen der Medizin, wie etwa der Neuro- logie (z.B. M. Parkinson), Kardiologie (z.B. Atherosklerose) und Geriatrie, hat dieses Forschungsgebiet stark an Bedeutung zugenommen [13]. Ein ähnlicher Ansatz könnte für die Augenheilkunde und insbesondere für die Untersuchung der Entzündungsprozesse im Auge von großem Nutzen sein. Diese Herangehensweise ist in der Ophthalmologie jedoch noch neu, und die meisten in der Augenheilkunde tätigen Forscher verfügen nur über ein begrenztes Wissen in diesem neu aufkommenden Bereich.

Das Trockene Auge ist eine entzündliche Erkrankung, bei der sowohl metabolische als auch immunregulatorische Störungen eine Rolle spielen. Auf der Augenoberfläche befinden sich verschiedene mikrobielle Organismen, die am Metabolismus der Augenoberfläche beteiligt sind. Pathologische Veränderungen in der Zusammensetzung der Mikroben auf der Augenoberfläche können eine Immunreaktion auslösen. Im Folgenden werden die metabolischen und immunologischen Veränderungen sowie die Veränderungen der mikrobiellen Zusammensetzung, die mit der Pathogenese des Trockenen Auges assoziiert sind, erörtert. Die vorliegende Übersichtsarbeit soll die Lücke im Verständnis der Pathogenese des Trockenen Auges schließen und Möglichkeiten identifizieren, die Behandlung und Versorgung des Trockenen Auges zu verbessern.

\section{DES-assoziierte metabolische Dysregulation}

Oxidativer Stress aktiviert an verschiendenen Stellen die DESassoziierte pathologische Kaskade (Abb. 1). Reaktive Sauerstoffspezies (reactive oxygen species, ROS) schädigen die Becherzellen, die Myelinscheiden der Nerven der Augenoberfläche und die Lipidschicht des Tränenfilms. Dadurch wird die Lipidschicht des Tränenfilms instabil und es kommt zu einer inflammatorischen Dysregulation [14]. Die Instabilität des Tränenfilms hat zur Folge, dass die Osmolarität steigt und oxidative 
Bedingungen auf der Augenoberfläche entstehen. Wurden primäre humane Hornhautepithelzellen (human corneal epithelial cells, HCECs) hyperosmolaren Medien ausgesetzt, führte dies zu einem signifikanten Anstieg reaktiver oxidativer Substanzen, gemessen mittels $2^{\prime}, 7^{\prime}$-Dichlorfluoresceindiacetat, einem membranpermeablen Stoff, der bei oxidativem Stress in den Zellen oxidiert wird, wodurch stark fluoreszierendes $2^{\prime}, 7^{\prime}$-Dichlorfluorescein (DCF) entsteht. Die Konzentration der toxischen Produkte der Lipidperoxidation, 4-Hydroxynonenal (4-HNE) und Malondialdehyd (MDA) nahm dosisabhängig mit steigender Osmolarität der Medien zu, und es war eine Verminderung der antioxidativen Enzyme wie Superoxid-Dismutase (SOD) und Glutathionperoxidase (GPx) in den humanen Hornhautepithelzellen nach Exposition gegenüber hyperosmotischen Medien zu beobachten [15]. Eine andere Untersuchung zeigte, dass bei Kultivierung von humanen Hornhautepithelzellen in hyperosmotischen Medien (550-550 mOsm) die DCF-Färbung und die mRNA-Expression des NLR family pyrin domain containing 3 (NLRP3)-Inflammasoms, einschließlich NLRP3, apoptosis-related speck-like protein (ASC), Pro-Caspase und Pro-Interleukin (IL)-1 $\beta$ zunahmen. Zudem wurden diese Erhöhungen durch die Zugabe von $n$-Acetylcystein als Antioxidans zum Medium gehemmt. Interessanterweise kam es bei Stummschaltung der NLRP3-Expression durch small interfering RNA in humanen Hornhautepithelzellen, die hyperosmotischen Bedingungen ausgesetzt waren, zu einem Rückgang der ASC-, Procaspaseund $I L-1 \beta$-mRNA-Konzentration. Bei DES-Patienten sind alle diese Faktoren sowie die ROS-Spiegel erhöht [16]. Chi et al. [17] berichteten über eine erhöhte Expression von $I L-1 \beta$ und $I L-18$ nach Verringerung der NLRP3-Konzentration durch Gabe von Glibenclamid bei Mäusen, bei denen ein experimentelles Trockenes Auge (Desiccating Stress Model, DS) induziert wurde. Darüber hinaus führte die Behandlung mit einem Caspase-1-Inhibitor (z-YVAD fmk) nicht zu einer veränderten NLPR3-Aktivität, sondern $\mathrm{zu}$ einer signifikanten Wiederherstellung der durch hyperosmolaren Stress herunterregulierten NRLP6-Bildung (eine Komponente des Inflammasoms). Zudem kann Caspase-8 die NLRP3-Aktivierung sowie die nachgeschalteten Signalwege stimulieren. Diese Ergebnisse zeigen, dass hyperosmolarer Stress durch oxidativen Stress eine Beschleunigung der Immunkaskade auslöst, was unterschiedliche Angriffspunkte für eine mögliche Prävention und Behandlung des Trockenen Auges bietet.

Es existieren verschiedene antioxidative Mechanismen, die den oxidativen Stress kompensieren. Liu et al. [18] bestimmten die Konzentration der Proteine Sirtuin 1, FOXO3 und Mangan-Superoxid-Dismutase (SOD) bei diabetischen DES-Mäusen. Dabei beobachteten sie in Woche 1 und 4 in der diabetischen DESGruppe höhere Konzentrationen als in der Nicht-DES-Gruppe, wobei die Werte in Woche 8 allerdings zurückgingen. Die Autoren führten diese Beobachtung auf Kompensationsmechanismen zurück, die die Konzentration antioxidativer Moleküle bei diabetischen Mäusen erhöhen; diese Kompensationsmechanismen waren in Woche 8 jedoch erschöpft.
Immunsystem und Immunmetabolismus beim Trockenen Auge Aktuellen Modellen zufolge sind Th17 (T-Helfer 17) (IL-17-sezernierende CD4+T-Zellen) und Th1-Zellen die wichtigsten Immunmediatoren beim Trockenen Auge [19] und sie werden durch den CC-Motiv-Chemokin-Rezeptor 6 (CCR6) bzw. CCR3 zur Augenoberfläche rekrutiert. Coursy et al. [20] berichteten, dass beim Trockenen Auge die Zahl der CCR6+CD4+- und CCR3+CD4+T-Zellen auf der Augenoberfläche sowie in den regionären Lymphknoten zunimmt, die in der Folge IL-17 und Interferon (IFN)- $\gamma$ sezernieren. Das Ausschalten dieser beiden Rezeptoren verhindert zudem die Störung der kornealen Barrierefunktion, die T-Zell-Infiltration und den Rückgang an Becherzellen als Reaktion auf das Trockene Auge. Ferner verhindert das Ausschalten des CCR3-Rezeptors die Störung der kornealen Barrierefunktion und die T-Zell-Infiltration, bewirkt jedoch keine Verminderung des Becherzellverlusts als Reaktion auf das Trockene Auge; dagegen führt die Sekretion von IFN- $\gamma$ zu einem Rückgang der Becherzellen beim Trockenen Auge [21, 22].

Th17-Zellen wandern zur Augenoberfläche, indem sie auf ihrer Oberfläche CCR6 exprimieren. CCR6 bindet an CCL20 (C-C motif chemokine ligand 20), der auf dem Epithel der Augenoberfläche exprimiert wird und dessen Expression bei DES-Patienten erhöht ist. Demgegenüber verringert eine Blockade durch AntiCCL20-Antikörper die Vermehrung der Th17-Zellen und ihre Infiltration der Augenoberfläche beim Trockenen Auge und verbessert die klinischen Symptome, wohingegen die Zytokinexpression (IL-6, IL-23, Tumornekrosefaktor (TNF)- $\alpha$ und IFN- $\gamma$ ) steigt. $\mathrm{CD} 11 \mathrm{~b}+$ Zellen sind antigenpräsentierende Zellen (APCs), die bei Entzündungszuständen in die Hornhaut rekrutiert werden. Unter Behandlung mit subkonjunktivaler Injektion eines Anti-CCL20Antikörpers nimmt die Infiltration der Hornhaut durch CD11b+ Zellen ab [23]. In Mausmodellen verringert die Behandlung mit einem Antikörper gegen Granulozyten-Kolonie-stimulierenden Faktor darüber hinaus in vivo und in vitro die Migration und Reifung (Expression des major histocompatibility complex (MHC) II) von CD11b+ dendritischen Zellen (dendritic cells, DCs) an der Augenoberfläche und verbessert die klinischen Symptome des Trockenen Auges. Außerdem rekrutiert der Granulozyten-Makrophagen-Kolonie-stimulierende Faktor (GMCSF) CD11b+ antigenpräsentierende Zellen zur Augenoberfläche. Es wurde gezeigt, dass die Heraufregulation von GM-CSF auf der Augenoberfläche beim Trockenen Auge auf Th17-Zellen zurückzuführen ist [24].

IFN- $\gamma$ ist ein inflammatorisches Zytokin, das von Th1-Lymphozyten gebildet wird und die zellulären Veränderungen der DESProgression vermittelt [25]. IFN- $\gamma$ vermindert die wässrige Phase des Tränenfilms (aqueous tear deficiency, ATD; sowohl bei Sjögren- als auch bei Nicht-Sjögren-Syndrom), wobei das Verhältnis IL13 : IFN- $\gamma$ in beiden ATD-Gruppen im Vergleich zu den Kontrollen verringert ist [26]. Muzinproteine fördern die Becherzelldichte, und die mucin 5AC (MUC5AC)-Transkripte waren in beiden ATD-Gruppen vermindert, wohingegen die Konzentration an konjunktivalem IFN- $\gamma$ negativ mit der Höhe des Tränenmenis-
66

Kompass Ophthalmol 2020;6:64-75 DOI: $10.1159 / 000507467$ 
kus (tear meniscus height, TMH) und der konjunktivalen Becherzelldichte korreliert war. Darüber hinaus waren die small proline rich protein 2G-Transkripte bei Patienten mit ATD erhöht und es bestand eine positive Korrelation mit den IFN- $\gamma$-Konzentrationen. IFN- $\gamma$ und IL-13, die von Th2-Lymphozyten freigesetzten inflammatorischen Zytokine, stimulieren die Proliferation von gering differenzierten Becherzellen und die Expression von MUC5AC [27]. Daneben stimuliert IL-13 die Expression des FasLiganden, von CCL26, des Calcium-aktivierten Chloridkanals 3, des trefoil factor 3 und des Resistin-ähnlichen Moleküls $\beta$, die als apoptotischer Rezeptor auf Lymphozyten, als chemotaktischer Faktor von CD4+ Th-Zellen, Eosinophilen und Basophilen und als Marker für die Hyperplasie und sekretorische Aktivität der Becherzellen bzw. als Reparatur- und Erhaltungsfaktor für die Barrierefunktion des Mukosaepithels wirken. IFN- $\gamma$ hemmt in Mausmodellen die Proliferation der Becherzellen [22] und erhöht die Konzentration der Proteine, die an der Antwort auf ungefaltete Proteine (unfolded protein response, UPR) beteiligt sind, wodurch die Translation der MUC2- und MUC5AC-mRNA gehemmt wird. Die Behandlung von Becherzellkulturen mit Dexamethason reduziert die IFN- $\gamma$-vermittelte Caspase-3- und UPR-bezogene Aktivität und verhindert dadurch einen Rückgang der MUC5AC-Konzentration. Im Bindehautepithel von Patienten mit Sjögren-Syndrom ist die Konzentration von glucoseregulated protein $78 \mathrm{kD}$ und gespleißtem X-box-binding protein-1 signifikant erhöht. Nach Garcia-Posadas et al. [28] erhöht IFN- $\gamma$ die intrazelluläre Kalziumkonzentration, wohingegen es den cholinergen intrazellulären Kalziumanstieg hemmt. Ferner verhindert eine langanhaltend erhöhte IFN- $\gamma$-Konzentration die cholinerge Stimulation der Muzinbildung durch die Becherzellen, indem sie den JAK-STAT (Janus kinase-signal transducer and activator of transcription)-Signalweg aktiviert.

Chen et al. [19] berichteten, dass die konjunktivale mRNA-Expression von Th17-assoziierten Zytokinen (IL-17A, IL-6 und $I L-$ 23) bei DES-Patienten erhöht war, wobei die Konzentration von $I L-17 A$ und $I L-6$ bei Patienten mit Sjögren-DES höher ausfiel als bei Patienten mit Nicht-Sjögren-DES und kein signifikanter Unterschied in den $I L-23$-Konzentrationen zwischen den Gruppen bestand. Interessanterweise korrelierte die Konzentration dieser Zytokine mit DES-spezifischen Parametern der Augenoberfläche, wie dem OSDI (Ocular Surface Disease Index), der Tränenfilmaufreißzeit (tear-film break-up time, TBUT), dem Schirmer I-Test und der Fluorescein-Färbung der Hornhaut [29].

IL-17, das von Th17-Zellen gebildet wird, induziert die B-Zell-Proliferation und -Differenzierung, und sowohl Th17- als auch Th1Zellen bewirken eine signifikante Erhöhung der B-Zell-Proliferation, wobei dieser Effekt bei Th17-Zellen stärker ausgeprägt ist als bei Th1-Zellen. IL-17 steigert die Proliferation von autoreaktiven B-Zellen nach Stimulation mit Anti-CD40- und Anti-IgM-Antikörpern, die zudem eine erhöhte Expression des IL-17-Rezeptors auf der Oberfläche der B-Zellen zur Folge hat. Darüber hinaus führt die Sekretion von IL-17 und IFN- $\gamma$ zu einer vermehrten BZell-Differenzierung und -Proliferation, den Hauptfaktoren der DS-induzierten Schädigung der Augenoberfläche [30].
Die adaptive Immunantwort fördert DES-spezifische Entzündungsprozesse, doch erfordert die primäre Aktivierung dieser Kaskade keine Beteiligung der Th-Zellen. Desiccating Stress (DS) bewirkt die Bildung der MHC-I-verwandten Proteine A und $\mathrm{B}$, die IFN- $\gamma$-bildende natürliche Killerzellen (NK) aktivieren. Dadurch kommt es zur Freisetzung von Th1-bezogenen Chemokinen durch die Epithelzellen der kornealen Konjunktiva, welche die Infiltration von Th1-Zellen fördern. Die Initialphase dieses Prozesses wird durch die Abwesenheit von Th1-Zellen jedoch nicht gehemmt, was zeigt, dass das angeborene Immunsystem von entscheidender Bedeutung für die Einleitung der IFN- $\gamma$ Freisetzung zur Bildung von Th1-bezogenen Chemokinen ist [31].

Sowohl CD4+ als auch CD8+ regulatorische T-Zellen (Tregs) unterdrücken den Entzündungsprozess beim Trockenen Auge [32]. In Mausmodellen führte die Depletion oder Inaktivierung von CD8+ T-Zellen durch Anti-CD8-Antikörper zu einer vermehrten Hornhautinfiltration durch CD4+ T-Zellen und erhöhte deren Konzentration in den drainierenden zervikalen Lymphknoten. Zudem nahm die Bildung von IL-17A sowohl durch Zellen der Augenoberfläche als auch durch CD4+ T-Zellen zu, wohingegen die Bildung von IFN- $\gamma$ durch die Zellen der Augenoberfläche und die IL-13-Konzentration in CD4+ T-Zellen zurückgingen. Darüber hinaus führte die Depletion CD8+ T-Zellen zu einer gesteigerten Pathogenität der Th17-Zellen und zu einer erhöhten Bildung von IL-17 und CCL20 sowie im weiteren Verlauf zu erhöhten Matrix-Metalloproteinase(MMP)-3- und MMP-9-Konzentrationen, die bei der DS-induzierten Störung der kornealen Barrierefunktion eine zentrale Rolle spielen.

UnterDS-BedingungensteigtdieKonzentrationvon CD8+CD103+ T-Zellen, die auf der Augenoberfläche und in den zervikalen Lymphknoten eine immunregulatorische Funktion haben. Der Co-Transfer von CD8+CD103+ Tregs bewirkt jedoch keine Suppression der pathogenen Th17-Antwort auf der Augenoberfläche, was darauf hindeutet, dass diese Tregs die Bildung pathogener Th17-Zellen vor ihrer Initiierung unterdrücken, indem sie die DCAktivierung supprimieren [31].

Die metabolischen Faktoren der Mikroumgebung tragen wesentlich zur Differenzierung von CD4+ T-Zellen in Th17- oder TregZellen bei (siehe Abb. 2). Unter Th17-förderlichen Bedingungen nehmen CD4+ T-Zellen Glukose auf und gehen zur aeroben Glykolyse über, wohingegen sie unter antiinflammatorischen Bedingungen Lipide aufnehmen und diese zur Energiegewinnung oxidieren [33]. In einem inflammatorischen Mikromilieu, das Folge der DS-Bedingungen ist, können Tregs in «exTreg»-Zellen umgewandelt werden. Aufgrund ihrer phänotypischen Plastizität sind CD4+CD25+forkhead box P3 (Foxp3)+ T-Zellen unfähig, Foxp3 in einem entzündlichen Mikromilieu zu exprimieren [34]. Diese exTregs exprimieren IL17 und IFN- $\gamma$ und bewirken keine Suppression der Entzündungsreaktion [35].

Ein weiterer wichtiger Faktor des angeborenen Immunsystems beim Trockenen Auge ist die proinflammatorische Wirkung der neutrophil extracellular trap (NET), bei der es sich um einen Komplex aus extrazellulärer DNA (eDNA), Histonen, Cathelici- 
Abb. 2. Metabolische Anforderungen der Th17und Treg-Reaktionen. Th17-Zellen benötigen einen aeroben glykolytischen Stoffwechsel. Induktoren des oxidativen Lipidstoffwechsels hemmen die Bildung von Th17-Zellen. Umgekehrt wird die Bildung von Treg-Zellen durch Therapien, die den oxidativen Lipidstoffwechsel fördern, verstärkt und durch Inhibitoren des Lipidtransports wie etwa Etomoxir supprimiert. Für die Th17-Zelldifferenzierung sind Cholesterinderivate erforderlich, und die Blockade der Cholesterinbiosynthese, beispielsweise mit Ketoconazol, unterdrückt die Bildung von Th17-Zellen, hat jedoch keinen Einfluss auf die Treg-Zellen. Abbildung mit freundlicher Genehmigung entnommen aus Binger, K.J. et al. [33].

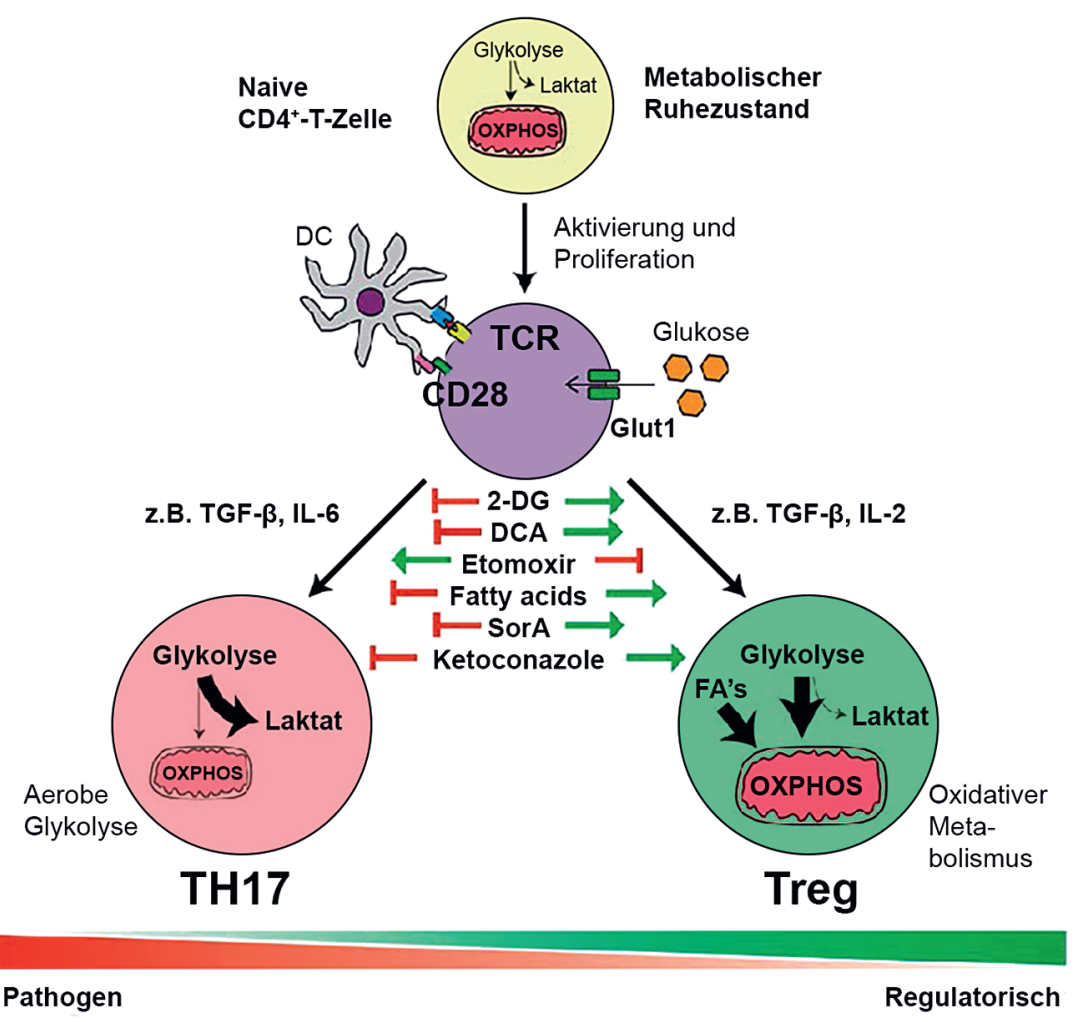

Pathogen
Regulatorisch din und neutrophiler Elastase handelt. Extrazelluläre DNA wird aus abgestorbenen Epithelzellen freigesetzt, deren Zahl beim Trockenen Auge aufgrund des erhöhten Epithelzellumsatzes zunimmt, und Neutrophile sind eine wesentliche Quelle der NETBildung. Im Tränenfilm von DES-Patienten ist zudem die Nuklease- und DNase I-Aktivität herabgesetzt, was den eDNA-Abbau zusätzlich vermindert. Diese Daten sprechen dafür, dass die Bildung und Akkumulation von NET im Tränenfilm eine der wichtigsten Ursachen für die Entzündung der Augenoberfläche beim Trockenen Auge ist [36].

Derzeit wird die LFA-1/ICAM-1-Interaktion als neues therapeutisches Ziel beim Trockenen Auge erforscht [37]. Die LFA-1/ ICAM-1-Interaktion spielt eine zentrale Rolle bei der zellvermittelten Immunantwort und bei der Entzündung, die mit den immuninflammatorischen Mechanismen beim Trockenen Auge verbunden ist. Die Blockade der Bindung von LFA-1 und ICAM-1 mit Lifitegrast könnte ein neuartiger Ansatz sein, um die zellvermittelte Immunantwort und Entzündung der Augenoberfläche gezielt zu bekämpfen.

DES-assoziierte Veränderungen des normalen Mikrobioms Eine wichtige neue Front bei der Erforschung von Schleimhautentzündungen ist die Analyse des Mikrobioms. Der menschliche Körper beherbergt ein sehr vielfältiges Mikrobiom von mindestens 1000 Spezies [38]. Auf der Haut und den Schleimhäuten von Augen, Nase, Nasen-Rachen-Raum und Genitalien befinden sich 10-100 Billionen mikrobielle Zellen, die in einem empfindlichen
Gleichgewicht mit dem Immunsystem des Wirts koexistieren [39, 40]. Wie sich gezeigt hat, ist die direkte Interaktion der Signalwege (Crosstalk) zwischen residenten Mikroben und den Immunzellen des Wirts in der Schleimhaut eine Schlüsseldeterminante für die Entzündungsreaktion bei Krankheitszuständen [41]. Insbesondere werden Th-17- und Treg-Zellen durch das menschliche Mikrobiom beeinflusst (s. Abb. 1 und Abb. 3). Darüber hinaus ist das Mikrobiom als ein wichtiger Faktor am Schleimhautmetabolismus beteiligt. Residente Bakterien bilden ein breites Spektrum an Metaboliten, tragen zur Metabolisierung von Arzneimitteln auf der Schleimhaut bei und beeinflussen dadurch immunmetabolische Prozesse und die Pharmakotherapie [42-45].

Es gibt verschiedene idiopathische Krankheiten, die die Augenoberfläche betreffen, darunter, aber nicht ausschließlich, das Trockene Auge, follikuläre Konjunktivitis, Pterygium und die Thygeson-Krankheit. Grundlegendes Element all dieser Erkrankungen ist die inflammatorische Dysregulation, und es ist folgerichtig anzunehmen, dass die Dysregulation des normalen okulären Mikrobioms an vielen oder allen dieser Krankheiten beteiligt ist [46]. Veränderungen des mukosalen Mikrobioms verändern die Schleimhautimmunität und die Reaktion des Wirts auf eine umweltbedingte Schädigung und lösen dadurch eine Autoimmunreaktion, wie beispielsweise eine entzündliche Darmerkrankung, aus [47, 48]. Paiva et al. [49] berichteten über einen Rückgang der operativen taxonomischen Einheiten (operational taxonomic unit, OTU) im Stuhl von Mäusen, die Antibiotika erhielten und DS ausgesetzt waren, nach 10 Tagen. Dabei kam es zu einer Ab-
68

Kompass Ophthalmol 2020;6:64-75 DOI: $10.1159 / 000507467$ 


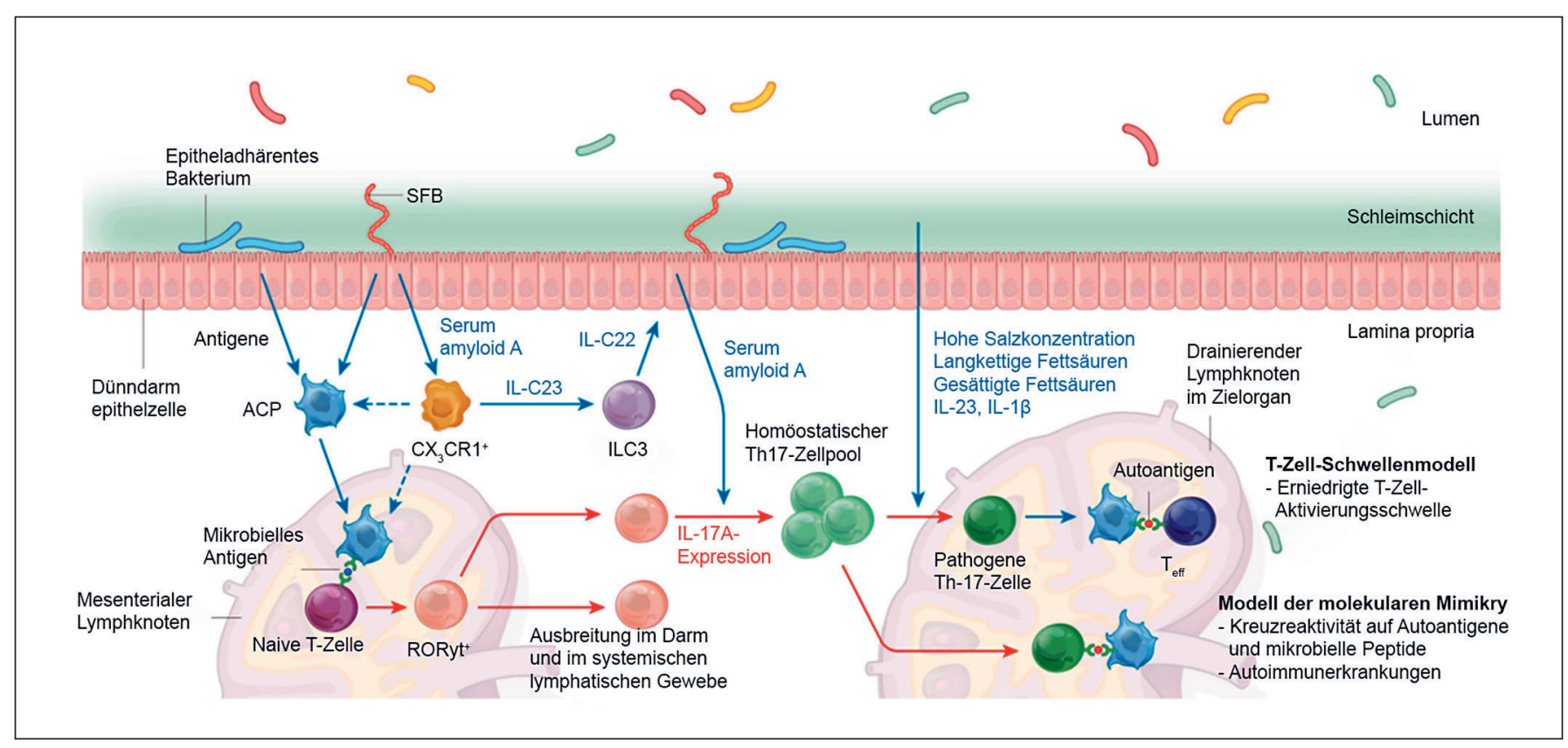

Abb. 3. Mikrobiom und Th17-Autoimmunität. Untersuchungen des Mikrobioms der Darmschleimhaut zeigten einen Zusammenhang mit der Th17-Antwort und der Epithelintegrität. Diese Studien könnten für Wissenschaftler von Nutzen sein, die an anderen Schleimhäuten forschen. Ferner wurden direkte Verbindungen zwischen dem intestinalen Mikrobiom und Augenkrankheiten diskutiert, darunter auch eine Verbindung mit Uveitis [50] und Trockenem Auge [49]. Abbildung mit freundlicher Genehmigung entnommen aus Kenya Honda et al. [51].

nahme der Bacteroidetes- und Firmicutes-Stämme und zu einer Zunahme der Proteobakterien nach DS-Exposition. Des Weiteren berichteten die Autoren über einen signifikanten Rückgang von Blautia, Alistipes, Lactobacillus, Allobaculum, Bacteroides, Desulfovibrio, Intestimonas und Clostridium, wohingegen Enterobacter, Parasutterella, Escherichia/Shigella, Pseudomonas und Staphylococcus signifikant zunahmen. Zudem fanden sich bei Mäusen unter Antibiotika und DS ein erhöhter Rückgang an Becherzellen, infiltrierende CD4+ T-Zellen im Bindehautepithel sowie eine Störung der kornealen Barrierefunktion im Vergleich zu Mäusen, die nur DS ausgesetzt waren. Die Genexpressionsanalyse zeigte, dass die Antibiotikagabe bei nicht gestressten (nonstressed, NS) B6-Mäusen im Vergleich zu NS-Mäusen, die keine Antibiotika erhalten hatten, im Bindehautgewebe einen $I L$ 17-Anstieg bewirkte und die IFN- $\gamma$-mRNA-Konzentration senkte. Demgegenüber führte die Kombination von Antibiotikatherapie und DS zu einem Anstieg der IFN- $\gamma$-mRNA-Spiegel sowie zu einem signifikanten Rückgang von $I L-13$ und des $I L-13: I F N-\gamma$ Verhältnisses [49]. Diese Ergebnisse sprechen dafür, dass die Antibiotikatherapie die Immunaktivität und die okuläre Reaktion auf DS verändern kann.

Das okuläre Mikrobiom hat einen starken Einfluss auf das metabolische Profil der Augenoberfläche und damit auf die Immunität der Augenoberfläche. Kurzkettige Fettsäuren, wie etwa Butyrat aus Butyrat-bildenden Bakterien (z.B. Faecalibacterium), spielen eine wichtige Rolle bei der Differenzierung von Treg-Lymphozyten [47], und erhöhte Populationen gramnegativer Bakterien könnten für die schweren Entzündungsreaktion bei DES-Patienten verantwortlich sein. Die Störung der Barrierefunktion der
Augenoberfläche durch Krankheiten wie das Trockene Auge aktiviert den Toll-like-Rezeptor (TLR)4-Signalweg [52]. Lipopolysaccharide (LPS) sind Endotoxine, die von gramnegativen Bakterien freigesetzt werden. Sie erhöhen die Expression von inflammatorischen Zytokinen in der Hornhaut (IL-1 $\beta$ und C-X-C motif Chemokin-Ligand (CXCL)10) und der Bindehaut (IL-1 $\beta$, CXCL10, IL-6, TNF $\alpha$, IL-12 $\alpha$ und IFN- $\gamma$ ), indem sie den TLR4-Signalweg aktivieren. Die Ergebnisse zeigen, dass eine veränderte mikrobielle Vielfalt der Schleimhäute und die Schleimhautdysbiose Auswirkungen auf die Treg-Differenzierung haben kann [53], und die Produkte der mikrobiellen Flora, wie beispielsweise LPS, können eine erhöhte Zytokinsekretion durch die Immunzellen verursachen. Die Daten deuten darauf hin, dass Veränderungen des normalen Mikrobioms zu einer abnormen Immunantwort führen (insbesondere über immunmetabolische Mechanismen), die ein Element der zugrunde liegenden Pathophysiologie beim Trockenen Auge ist (Abb. 1 und Abb. 3).

\section{Neue Messverfahren und Krankheitsmodelle}

\section{Klinische Ansätze}

Trotz der hohen Prävalenz existiert kein Goldstandard für die Diagnose des Trockenen Auges. Die klinischen Routineuntersuchungen korrelieren in sehr geringem Maße mit den Symptomen der Patienten und unterliegen zudem einem Beobachter-Bias [5456]. Es existieren verschiedene Untersuchungen zur Bewertung von Qualität und Quantität der Aspekte der Augenoberfläche und des Tränenapparats. Welche Untersuchungen in der Lage sind, das Trockene Auge mit akzeptabler Spezifität und Sensitivi- 
tät festzustellen, ist jedoch unklar [57]. In diesem Abschnitt liegt der Schwerpunkt auf der Beurteilung des Tränenvolumens und der Tränenosmolarität, die beim Trocken Auge, wie bereits erörtert, oxidativen Stress auf der Augenoberfläche verursachen, und es wird darüber hinaus auf andere neu entwickelte Verfahren zur DES-Beurteilung eingegangen.

Die Beurteilung des Tränenmeniskus (TM) erfolgt normalerweise mithilfe der Fluorescein-Färbung und mit dem Keratograph 4 lässt sich die TBUT nichtinvasiv messen. Die Interklassenwerte und die 95\%-Konfidenzintervalle der Übereinstimmung in der TBUT zwischen den Visiten und nach den Visiten, die mittels nichtinvasiver Keratographie und Fluorescein-Färbung gemessen wurde, zeigten, dass kein signifikanter Unterschied in der TBUT besteht [58]. Die TMH, die anhand von Aufnahmen eines OCULUS-Keratographen der vierten Generation ermittelt wurde, ist signifikant und positiv mit der TBUT und dem Schirmer-Test korreliert [59]. Vor kurzem wurden verschiedene optische Kohärenztomographie-Systeme (OCT) zur Messung der TMH untersucht, und nach Raj et al. [60] bestand keine signifikante Korrelation zwischen der TM-Fläche, die mittels Fourier Domain OCT (FD-OCT) bestimmt wurde, TBUT und dem Ergebnis des Schirmer-Tests. Darüber hinaus berichteten Fukuda et al. [61] eine signifikante Korrelation zwischen dem oberen TM-Volumen, dem unteren TM-Volumen, und der unteren TMH bei Messung mit dem Schirmer-Test, jedoch nicht bei der TBUT. Eine andere Studie zeigte eine signifikante Korrelation zwischen der mittels Keratographie und mittels FD-OCT gemessenen TMH, wobei die Keratographie bei erhöhten TMH-Werten jedoch tendenziell niedrigere Ergebnisse liefert [62]. Einige andere Messverfahren haben die Beurteilung der Hyperosmolarität zum Ziel [1, 63]. Üblicherweise wird die Osmolarität der Tränenflüssigkeit mittels Gefrierpunktabsenkung und Dampfdrucktechnik gemessen; diese Verfahren sind jedoch nicht sichtbar und werden durch den reflektorischen Tränenfluss bei der Probennahme eingeschränkt [64]. Rocha et al. [65] verglichen die Genauigkeit und Präzision des Dampfdruckosmometers Wescor 5520, des TearLab-Osmolaritätssystems und des i-Pen zur Bestimmung der Osmolarität der Tränenflüssigkeit. Sie stellten fest, dass die Ergebnisse der beiden erstgenannten Geräte signifikant korrelierten und genau und präzise waren, während die Ergebnisse des dritten Geräts nicht signifikant mit den anderen Geräten korrelierten und weniger genau ausfielen. Eine andere Studie, in der die Präzision und Genauigkeit des TearLab-Osmometers bei Verwendung der Gefrierpunkt-Senkungsmethode verglichen wurde, kam zu dem Schluss, dass die Ergebnisse der Osmolaritätsmessung selbst bei hyperosmolaren Lösungen genau und präzise waren [66]. Badugua et al. [67] stellten ein neuartiges Verfahren zur Bestimmung der individuellen Ionenkonzentrationen in der Tränenflüssigkeit mithilfe von Silikonhydrogel vor. Ihnen zufolge können mit diesem Ansatz sechs vorherrschende Ionenspezies in der Tränenflüssigkeit gemessen werden.

Kürzlich wurde das maximale Blinzelintervall (MBI), d.h. die Zahl der Sekunden, die die Augen ohne Lidschlag offen bleiben können, als Indikator für die Instabilität des Tränenfilms gemes- sen [68]. Die Autoren berichteten über ein signifikant kürzeres MBI in der DES-Gruppe gegenüber der Nicht-DES-Gruppe sowie über eine positive Korrelation zwischen MBI und TBUT und eine negative Korrelation zwischen dem MBI und der Fluorescein-Färbung der Hornhaut. Die Sensitivität betrug 82,5\% und die Spezifität 51,0\% für die Diagnose des Trockenen Auges mittels MBI; es sind jedoch weitere Untersuchungen erforderlich, die diese Ergebnisse bestätigen. Eine ähnliche Beurteilungsmethode ist das Intervall zwischen zwei Lidschlägen (inter-blinking interval, IBI), mit dem die normale Lidschlagrate ermittelt wird; man nimmt an, dass sie weniger mit kornealen und konjunktivalen Faktoren zusammenhängt als das MBI $[68,69]$. Da es sich bei den Ergebnissen der IBI-Studien um vorläufige Ergebnisse handelt, wurden daraus keine Schlussfolgerungen gezogen.

Wie in Abschnitt 2.1 erwähnt kann DES-assoziierter oxidativer Stress eine Instabilität der Tränenfilmlipidschicht zur Folge haben; daher kann die Beurteilung der Meibomdrüsen für die Diagnose des Trockenen Auges herangezogen werden. Die Keratographie und OCT-Systeme nutzen Infrarotstrahlung, um den Verlust an Meibom-Drüsen zu beurteilen. Palamar et al. [70] fanden in ihrer Untersuchung mittels OCT einen signifikanten Rückgang an Meibomdrüsen in den Unterlidern von Patienten mit okulärer Rosazea, nicht jedoch bei den gesunden Kontrollen. Finis et al. [71] führten eine Meibographie durch und verwendeten dafür den Keratograph 5M. Sie berichteten, dass das Ausmaß der Meibom-Drüsenatrophie im Unter- und Oberlid (MeiboScore) signifikant und invers mit der TBUT und positiv mit dem Alter korreliert war. Eine Alternative zur Beurteilung der Meibomdrüsenfunktion ist die konfokale mikroskopische Darstellung der Meibomdrüsenöffnung mittels TearScope und Meibomian Gland Evaluator, da sich damit die Dicke der Lipidschicht beurteilen lässt [72, 73]. Die MMP-9 ist ein weiterer quantifizierbarer Angriffspunkt für die Diagnose des Trockenen Auges [74, 75]. InflammaDry ist ein patientennah einsetzbarer MMP9-Immunoassay zur qualitativen Beurteilung der MMP-9-Konzentration in der Tränenflüssigkeit $[76,77]$. In einer Studie betrug die berichtete Sensitivität und Spezifität von InflammaDry bei der Diagnose des Trockenen Auges 85\% bzw. 94\% [78]. Die konjunktivale Impressionszytologie (conjunctival-impression cytology, CIC) von Bindehaut-Epithelzellen mittels Eyeprim erleichtert die Transkriptomanalyse. Das neue CIC-Gerät soll die Unannehmlichkeiten für die Patienten und den Bedarf an Anästhetika verringern; seine Wirksamkeit ist jedoch nicht bekannt $[68,69,79]$. Die Smartphone-Anwendung DryEyeRhythm erfasst umfangreiche individuelle Real-World-Daten und deckt Risikofaktoren wie weibliches Geschlecht, Kollagenerkrankung, saisonale allergische Rhinitis, Depressionen, das momentane Tragen von Kontaktlinsen, längere Bildschirmzeiten und Rauchen auf, die alle zu den schweren Symptomen vom DES-Typ beitragen [80]. Geräte, die zum Internet der medizinischen Dinge (internet of medical things, IoMT) gehören, wie Smartphones, könnten für die Telemedizin und Fernüberwachung eingesetzt werden [81].
70

Kompass Ophthalmol 2020;6:64-75 DOI: $10.1159 / 000507467$ 


\section{Molekulares Profiling und Omik-Ansätze}

Omik-Ansätze (Genomik, Transkriptomik und Proteomik) haben das Verständnis der molekularen Pathogenese von Augenkrankheiten verbessert, da sie einen nicht invasiven, leicht zugänglichen und individualisierten Ansatz bieten, um die Krankheitsmarker für die Diagnose und Therapie zu identifizieren.

Lipidomanalysen lieferten wertvolle Informationen zur Entwicklung des Trockenen Auges. Veränderungen in den Lipidprofilen der Augenoberfläche gehen mit klinischen Symptomen des Trockenen Auges einher. Nach Lam et al. [82] waren normale Werte von Cholesterylsulfaten (CSs), Glucosylceramiden (GluCers), NeuAca2-3Gal $\beta 1-4 G l c \beta$-Cers (GM3s), Lysophosphatidylcholinen (LPCs) und niedermolekularen Wachsestern (WEs) positiv mit dem Tränenvolumen korreliert. Außerdem beobachteten sie, dass die absoluten Konzentrationen dieser Moleküle mit abnehmender Tränensekretion sanken, wohingegen die Gesamtkonzentration der Lipide in der Tränenflüssigkeit sowie die molaren Anteile der Phosphatidinsäuren (PA) und Phosphatidylglycerine (PG) negativ mit dem Tränenvolumen korreliert waren. WEs, die gesättigte Fettsäuren, PA und PG enthielten, waren signifikant verringert, wohingegen der Schirmer-1-Test einen Konzentrationsanstieg zeigte. Dies ist möglicherweise auf die Bildung der oben genannten Lipide in den Tränendrüsen zurückzuführen. Lam et al. [83] beobachteten keine signifikanten Unterschiede bei den Lipiden der Meibomdrüsen in DES-Augen und gesunden Augen. Die Konzentration an ungesättigten Triacylglycerinen, einigen Phosphatidylcholinen, GluCers und Sphingolipid-Spezies war bei DES-Patienten jedoch erhöht. Eine andere Studie zeigte, dass eine 12-wöchige Wärmebehandlung des Lids zu einer starken Veränderung der Lipidzusammensetzung im Tränenfilm führte, wohingegen die Lipidmenge in der Tränenflüssigkeit unverändert blieb. Die Lysophospholipidklassen (d.h. Lysoplasmalogen-Phosphatidylethanolamine, LPCs und Lysophosphatidylinositole) waren nach der Behandlung verringert, während die Konzentration der jeweiligen diacylierten Gegenstücke anstieg. Darüber hinaus war die Konzentration an mehrfach ungesättigten Fettsäuren (polyunsaturated fatty acids, PUFAs), die Diacylglycerin enthielten, nach der Behandlung reduziert. Ferner korrelierten der Rückgang dieser Lipide und der Anstieg von O-Acyl$\omega$-Hydroxy-Fettsäuren (amphiphile Lipide) mit der Abnahme der Verdunstungsrate von Hornhaut und Sklera [84]. Einer anderen Studie zufolge bestand eine negative Korrelation zwischen 4-Hydroxynonenal und Malondialdehyd, zwei Markern der Lipidperoxidation, und der TBUT, dem Schirmer-Test, der Tränen-Clearance-Rate und der Becherzelldichte sowie eine positive Korrelation mit der Keratoepitheliopathie und der Symptompersistenz [85].

Die Proteomanalyse der Tränenflüssigkeit ist ein personalisierter Ansatz, der bei der Diagnose und Behandlung des Trockenen Auges zunehmend zum Einsatz kommt [86, 87]. Das am häufigsten eingesetzte Instrument zur Gewinnung von Tränenflüssigkeit und Proteinextraktion ist der Schirmer-Teststreifen [88], doch kann dieser mit einem Probenverlust verbunden sein. Um den Probenverlust zu verringern und die Zahl der identifizierten Proteine in der Tränenflüssigkeit zu erhöhen, wurden einteilige, filtergestützte Verfahren eingeführt [89]. Globale und gezielte Metabolomanalysen an humanen konjunktivalen Epithelzellen, die in serumfreien Medien bei $280 \mathrm{mOsm}$ (Kontrolle), $380 \mathrm{mOsm}$ und $480 \mathrm{mOsm}$ für 24 Stunden inkubiert wurden, ergaben, dass Carnitin das bevorzugte antiinflammatorische oder antiapoptotische Agens ist [90], während das als osmoprotektiv geltende Glycerophosphocholin der bevorzugte endogene Osmolyt ist. Nach diesen Ergebnissen deutet ein Anstieg der intermediären filamentartigen Keratinund Vimentinproteine darauf hin, dass es bei hyperosmotischem Stress zu einer Aktivierung des Zytoskelettumbaus kommt. Ferner berichteten die Autoren über eine Heraufregulation (Hitzeschockprotein $70-\mathrm{kDa}$ (HSP70)-5, dual-spezifische mitogen-aktivierte Proteinkinase 3, Prostaglandin-G/H-Synthase 2, Uridindiphosphat (UDP)-N-Acetylglucosamin-Pyrophosphorylase 1 und UDPN-Acetylglucosamin, interzelluläres Adhäsionsmolekül 1, IL-10, IL-17, Prostaglandin 2 und E2 sowie Prostacycline) und Herunterregulation (Plastin-2, 26S proteasome non-ATPase regulatory subunit 1 und Protein-Glutamine-gamma-Glutamyltransferase 2) von Proteinen [90]. In einer anderen Studie wurden die Proteomprofile von reflektorischen und basalen Tränen verglichen, wobei sich zeigte, dass die Konzentration von stark saurem, prolinreichen Protein (PRR) 4 in reflektorischen Tränen höher ist, was für eine mögliche Schutzfunktion dieses Proteins spricht. Diese Ergebnisse erweitern das derzeitige Wissen über die metabolischen Marker beim Trockenen Auge und stellen möglicherweise therapeutische Angriffspunkte dar. Einem anderen Bericht zufolge waren PRR 4 und das zymogen granule protein 16 homolog B in reflektorischen Tränen heraufreguliert; sie spielen möglicherweise eine sekretorische Rolle. Außerdem führt der erhöhte Serumaustritt bei reflektorischem Augentränen zu einem Anstieg von Serumalbumin in der Tränenflüssigkeit, und die heraufregulierte Mesothelinkonzentration in reflektorischen Tränen könnte eine gesteigerte Funktion von MUC16, das für Mucin kodiert, zur Folge haben. Die Konzentration des polymeren Immunglobulin (Ig)-Rezeptors und der Ig-Alpha-1-Ketten-C-Region, die hauptsächlich über den transcytotischen Weg sezerniert werden, war in reflektorischen Tränen ebenso vermindert wie Mammaglobin-B, Clusterin und Cystatin S/SN [91]. Diese Tränenflüssigkeitsproteine sind möglicherweise die wichtigsten Faktoren zum Schutz und Erhalt des dynamischen Gleichgewichts auf der Augenoberfläche von DES-Patienten. Und schließlich ist MMP-9 ein weiterer quantifizierbarer Angriffspunkt für die Diagnose des Trockenen Auges [74, 75]. InflammaDry ist ein patientennah einsetzbarer MMP-9-Immunoassay zur Beurteilung der MMP-9-Konzentration in der Tränenflüssigkeit $[76,77]$. In einer Studie betrug die berichtete Sensitivität und Spezifität von InflammaDry bei der Diagnose des Trockenen Auges 85\% bzw. $94 \%$ [78].

Das Trockene Auge, das bei systemischen Erkrankungen wie endokriner Orbitopathie (EO) bei Schilddrüsenerkrankung, Sjögren-Syndrom und Graft-versus-Host-Reaktion (graft-versushost-disease, GVHD) auftritt, wurde mithilfe von Proteomanalysen untersucht. Die EO ist die häufigste extrathyreoidale Manifestation des Morbus Basedow. Das Trockene Auge ist Folge 
einer Thyroidea-assoziierten Orbitopathie (TAO), bei der es zu einer Beteiligung der Tränendrüsen, Lidretraktion, Störung des Bell-Phänomens, vermindertem Blinzeln und Exophthalmus kommt [92]. Matheis et al. [93] analysierten das Proteom der Tränenflüssigkeit von TAO-Patienten mittels Massenspektrometrie. Ihre Untersuchung zeigte, dass TAO-Patienten erhöhte Entzündungsproteine (d.h. POTE ankyrin-domain family member 1) und eine Verringerung der protektiven und antiinflammatorischen Proteine (d.h. proline-rich lacrimal protein 1 (PROL1), PRP4 und Annexin A1) aufwiesen sowie ein signifikant unterschiedliches Protein-Panel (PRP4, PROL1 und UDP-Glucose-Dehydrogenase) im Vergleich zu DES-Patienten und gesunden Kontrollen. Daher könnte das Spektrum der inflammatorischen und protektiven Proteine ein hilfreicher Indikator für die DES-Aktivität bei Patienten mit TAO sein.

Das Sjögren-Syndrom ist eine Autoimmunerkrankung, die hauptsächlich die exokrinen Drüsen, insbesondere Speichel- und Tränendrüsen, betrifft [94]. Li et al. [95] untersuchten und verglichen das Proteom in der Tränenflüssigkeit von Patienten mit Sjögren-Syndrom mit dem von DES-Patienten und gesunden Probanden. Ihren Ergebnissen zufolge ist das Trockene Auge bei Patienten mit Sjögren-Syndrom mit einer Veränderung des Proteomprofils und einer gestörten Expression von Proteinen assoziiert, die an der Entzündung, Apoptose und Immunreaktion beteiligt sind und zum oxidativen Stress beitragen. Die Charakterisierung dieser Proteine würde potenzielle diagnostische Marker und therapeutische Angriffspunkte liefern.

Eine der Hauptursachen für Mortalität und Morbidität nach allogener hämatologischer Stammzelltransplantation (HSZT) ist die GVHD. Die Immunantwort schädigt das Gewebe von Bindehaut und Tränendrüsen, wodurch es zu einer Abnahme der Tränenproduktion und zum Trockenen Auge kommt [96]. Cocho et al. [97] berichteten einen signifikanten Rückgang der Konzentration an epidermalem Wachstumsfaktor sowie des Verhältnisses von interferon- $\gamma$ induced protein 10 (IP-10) zu CXCL10 in der Tränenflüssigkeit, wohingegen die Konzentration von IL-1Rezeptor- $\alpha$, das IL-8:CXCL8-Verhältnis und die IL-10-Spiegel im Vergleich zu gesunden Probanden signifikant erhöht waren. Cocho et al. schlugen ein prädiktives Modell für die Diagnose einer okulären GVHD auf der Grundlage des Verhältnisses von IP-10 zu CXCL10, adjustiert für Geschlecht und Alter, vor und fanden eine Sensitivität von $86,36 \%$ sowie eine Spezifität von $95,24 \%$ [97]. Jung et al. [98] beobachteten einen signifikanten Konzentrationsanstieg von IL-2, IL-10, IL-17a, IFN- $\gamma$, IL- 6 und TNFa in der Tränenflüssigkeit bei okulärer GVHD nach Anpassung für Alter, Geschlecht und Zeit nach HSZT, was den signifikanten und unabhängigen diagnostischen Nutzen dieser Zytokine zeigt. Außerdem korrelierten IL-10, IL- 6 und TNFa im Vergleich zu anderen Zytokinen am stärksten mit dem Schweregrad der GVHD [98].

Interessanterweise zeigten Analysen der okulären GVHD, dass bei einem signifikanten Anteil von Patienten mit hämatologischen Erkrankungen bereits vor der HSZT ein Trockenes Auge bestand $[99,100]$. Für eine frühzeitige Behandlung und zur Ver- ringerung potenzieller postoperativer Augenschäden wird eine umfassende ophthalmologische Beurteilung vor und nach einer HSZT empfohlen [101, 102].

\section{Biotechnologische Ansätze}

Die steigenden Forschungsausgaben für die Entwicklung neuer Medikamente [103] und der große Unterschied in der Wirkung von Medikamenten bei Menschen und anderen Spezies [104] haben dazu geführt, dass neue Techniken entwickelt wurden, um die menschliche Physiologie in präklinischen Studien zu modellieren [105]. Mit der Organ-on-a-Chip-Technologie wurden 3DTechniken eingeführt, die mithilfe von Mikrofluidik und Biotechnologie In-vivo-Bedingungen nachahmen [104]. Das humane blinzelnde Eye-on-a-Chip ist ein Beispiel für diese Technologie in der Augenheilkunde [106]. In diesem Modell werden 3D-Gerüste verwendet, die eine ähnliche Krümmung aufweisen wie die Hornhaut. Diese werden mit primären menschlichen Keratozyten imprägniert und zwischen einem Mikrofluidkanal und einer kreisförmigen Kammer eingebettet. Anschließend werden die Epithelzellen nach einem farbcodierten Verfahren auf die Gerüstoberfläche aufgebracht, wobei sich die grüne Fluoreszenz im Zentrum und die rote Fluoreszenz an der Peripherie der Gerüstoberfläche befindet. Im 3D-Drucker hergestellte Augenlider imitieren den normalen Lidschlag und werden elektromechanisch betätigt, wodurch die Ausbreitung des Tränenfilms und die Hydratation der Augenoberfläche reproduziert werden können. Das Hornhautorganoid, eine durch Tissue-Engineering erzeugte Miniatur-Kornea, ahmt In-vivo-Bedingungen nach und ermöglicht es so, die Organentwicklung sowie den Verlauf und die Behandlung von Krankheiten zu untersuchen. Eine alternative Quelle zu embryonalen Stammzellen für die Erzeugung von Organoiden sind pluripotente Stammzellen [107]. Mikrokornea oder Hornhautorganoide entstehen in späteren Stadien der retinalen Organoidbildung [108] und können für das Arzneimittelscreening sowie die Krankheitsmodellierung (z.B. DES) und als Gewebeersatz genutzt werden.

Da immunmetabolische Veränderungen eine entscheidende Rolle in der Pathogenese des Trockenen Auges spielen, ist es hilfreich, wenn immunologische und metabolische Faktoren in den biotechnologischen Modellen berücksichtigt werden. Vor kurzem entwickelten Jeongyun Seo et al. ein Eye-on-a-chip-Modell, mit dem sich die Pathogenese des Trockenen Auges nachahmen lässt [109]. Dieses Modell beinhaltet eine blinzelnde Hornhautoberfläche und kann zur Induktion eines DES-Phänotyps verwendet werden (s. Abb. 4). Jeongyun Seo et al. untersuchten die Expression von IL-8, TNF- $\alpha$, IL-1 $\beta$ und MMP-9 in ihrem Modell nach DES-Induktion und überwachten die Reaktion dieser Zytokine auf die DES-Therapie mit Lubricin.

\section{Neue Strategien zur Behandlung des Trockenen Auges}

Die Behandlung des Trockenen Auges hängt vom Schweregrad und möglicherweise vorliegenden Grunderkrankungen ab. Etwaige Systemerkrankungen müssen behandelt werden. Die wichDOI: $10.1159 / 000507467$ 

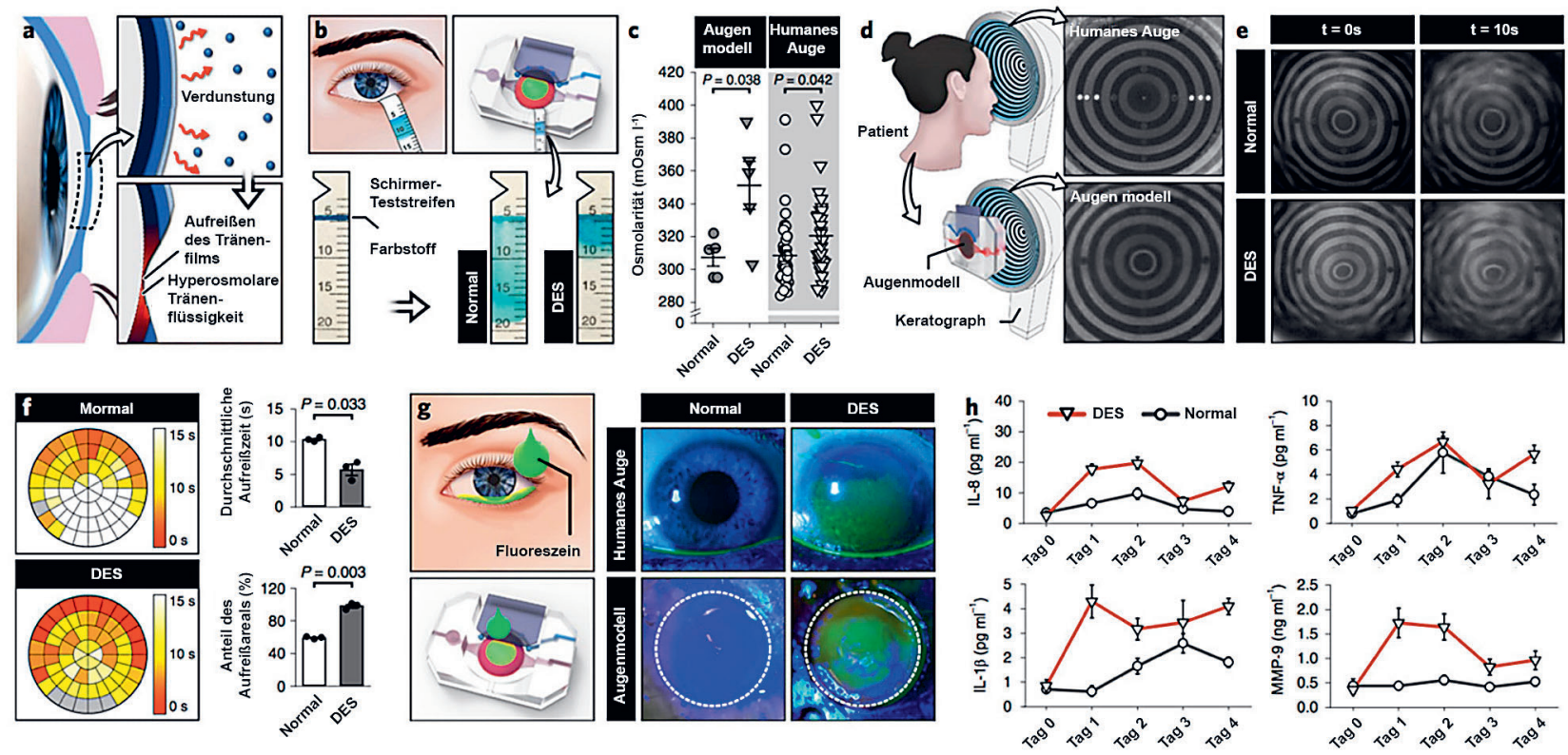

Abb. 4. Ein biotechnologisch erstelltes Modell für die evaporative Form des Trockenen Auges. (a) Durch Verdunstung kommt es zum Aufreißen des Tränenfilms und zu einer erhöhten Osmolarität der Tränenflüssigkeit. Beide Faktoren gemeinsam führen zu einem Verlust der Homöostase. (b) Absorption der Tränenflüssigkeit in die Schirmer-Teststreifen in Modellen zum gesunden Auge und zum Trockenen Auge. Die Absorption der Tränenflüssigkeit wird durch das Verwischen des blauen Farbstoffs in den Streifen sichtbar gemacht. (c) Osmolarität der Tränenflüssigkeit im DES-Modell (geschlossenes Dreieck) und im Modell zum gesunden Auge (geschlossener Kreis). Die klinischen Daten zur Osmolarität beim Menschen stammen von gesunden Probanden (offener Kreis) und von DESPatienten (offenes Dreieck). (d) Keratographie-Messungen, die konzentrische Ringe zeigen, die auf die Oberfläche des menschlichen Auges (oben) und auf die biotechnologisch erzeugte Augenoberfläche (unten) projiziert werden. (e) Repräsentative Aufnahmen der projizierten Ringmuster auf der biotechnologisch erzeugten Augenoberfläche im Modell zum gesunden Auge (obere Reihe) und im DES-Modell (untere Reihe), aufgenommen bei $t=0 \mathrm{~s}$ (linke Spalte) und $\mathrm{t}=$ $10 \mathrm{~s}$ (rechte Spalte). (f) Räumliche Darstellung der Tränenfilmaufreißzeit im Modell zum gesunden Auge (oben) und im DES-Modell (unten). Die verschiedenen Farben in den repräsentativen kreisförmigen Heatmaps entsprechen unterschiedlichen Aufreißzeiten. (g) Fluorescein-Färbung im Augenmodell und bei menschlichen Probanden. (h) Konzentrationen von Entzündungsmediatoren (IL-8, TNF-a, IL-1 $\beta$ und MMP-9) in der gesunden (Kreis) und in der DES-Gruppe (Dreieck), dargestellt gegen die Kultivierungsdauer. Abbildung mit freundlicher Genehmigung entnommen aus Jeongyun Seo et al. [109].

tigsten therapeutischen Strategien sind die Verbesserung der Tränenzusammensetzung und -menge durch künstliche Tränen, Anwendung entzündungshemmender Medikamente, Änderung der Ernährung und des Lebensstils sowie die Behandlung von assoziierten Liderkrankungen.

Anstatt wiederholt Tropfen zu verabreichen, können winzige scheibenförmige Membranen, so genannte Nanowafer, die Medikamente enthalten, auf das Auge aufgebracht werden, um eine anhaltende Medikamentenfreisetzung zu erzielen. Die anhaltende Freisetzung von Dexamethason durch beladene Nanowafer zeigte eine äquivalente Wirkung wie (oral oder topisch) zweimal täglich verabreichtes Betamethason. Außerdem stellte sie die Gleitfähigkeit der Augenoberfläche und die Barrierefunktion des Hornhautepithels wieder her und senkte gleichzeitig die Konzentration entzündlicher Zytokine [110]. Eine andere Untersuchung ergab, dass auf Nanowafer geladenes Dexamethason die Expression entzündlicher Zytokine, insbesondere in späteren Entzündungsstadien, verringerte [111]. Zudem bewirkte die Behandlung mit Fluormetholon $0,1 \%$ in einer vehikelkontrollierten klinischen Studie die Erhaltung der Hornhautintegrität unter Umweltbelas- tung [112]. Immunmodulatorische Medikamente modifizieren die Funktion des Immunsystems in der Behandlung von Autoimmunerkrankungen. Rapamycin (Sirolimus) ist ein immunmodulatorisches Arzneimittel, das die bei Trockenem Auge auftretende Entzündung verringert. Die Behandlung nicht adipöser diabetischer Mäuse (non-obese diabetic mice, NOD) mit Rapamycin zweimal täglich über 12 Wochen reduzierte die Lymphozyteninfiltration in Tränendrüsenlysaten. Nach topischer Verabreichung von Rapamycin kam es darüber hinaus zu einer erhöhten Tränensekretion trotz unveränderter Becherzelldichte, wohingegen die Kathepsin-S-Spiegel in den Tränendrüsen und in der Tränenflüssigkeit der Mäuse abnahmen [113].

Essentielle Fettsäuren modulieren die Funktion des Immunsystems durch Umwandlung in pro- und antiinflammatorische Zytokine; nach einer früheren Studie werden $\omega 3$-Fettsäuren in antiinflammatorische Zytokine und $\omega 6$-Fettsäuren in proinflammatorische Zytokine umgewandelt [114]. Die Ergebnisse zeigten, dass die Einnahme von $\omega 3$-Supplementen über 90 Tage die Tränenosmolalität, OSDI, Augenrötung und die Einfärbung der Augenoberfläche verringerte und so eine erhöhte Stabilität des Trä- 
nenfilms bewirkte, und dass diese Effekte bei der Verwendung der Phospholipidform von w3-Fettsäuren (Krillöl) im Vergleich zur Triacylglyceridform (Fischöl) verstärkt auftrat [115]. Nach Ovarektomie kommt es gemäß den Schirmer-Testergebnissen zu einem Rückgang der Tränenproduktion. Durch Supplementierung mit n-3-PUFAs, Docosahexaensäure (DHA), Eicosapentaensäure (EPA) und $\alpha$-Liponsäure wurde die Tränenproduktion jedoch teilweise wiederhergestellt, während nur alkalische Phosphatase (ALP) eine vollständige Wiederherstellung erreichte. Die Superoxid-Dismutase- und Aconitasespiegel blieben nach Ovarektomie oder unter Fettsäure-Supplementierung unverändert, während die Supplementierung mit ALP zu einer erhöhten Aktivität der GPx führte. Außerdem bewirkte die Ovarektomie eine Abnahme der Nitrit- und Stickoxidspiegel auf der Augenoberfläche, die durch ALP in der Hornhaut, nicht jedoch durch Fettsäuren in der Bindehaut wiederhergestellt wurden. Darüber hinaus stellten DHA, EPA und ALP die Nitrit- und Stickoxidspiegel in den Tränendrüsen wieder her, und EPA und DHA erhöhten zudem die Malondialdehyd-Konzentration in den Tränendrüsen. DHA, EPA und ALP wirken, indem sie den Verlust von Mikrovilli, Unregelmäßigkeiten in den Zellkontakten und die ovarektomiebedingte Desquamation der Zellen verhindern [116]. Den Ergebnissen einer anderen Studie zufolge verbesserte die orale Supplementierung mit Omega-3-Fettsäuren bei Computernutzern mit symptomatischem Trockenem Auge die TBUT sowie die Ergebnisse des Schirmer-Tests und veränderte gleichzeitig die Zytologie der Becherzellen und der Epithelzellen [117]. Die Verabreichung von topischen 0,2\%igen Omega-3-Fettsäuren in Kombination mit Hyaluronsäure verringerte den Schweregrad der Hornhautunregelmäßigkeit, die sich im Vergleich zu den Ergebnissen unter Hyaluronsäure als Monotherapie oder in Kombination mit 0,02\%igen Omega-3-Fettsäuren signifikant verbesserte [118]. Ferner wird durch die Zugabe von Mineralöl zu Augentropfen die Dicke der Lipidschicht an der Augenoberfläche von Patienten mit Meibom-Drüsen-Dysfunktion (MDD) signifikant erhöht und ein Verdunsten des Tränenfilms verhindert [119].

Das Erwärmen des Lids bewirkt eine Verflüssigung der MeibomDrüsensekrete und erleichtert deren Freisetzung auf den Tränenfilm. Zum Erwärmen des Lids können Augenmasken oder EyeBag-Kompressen verwendet werden. Die Temperatur des äußeren und inneren Augenlids stieg bei Verwendung einer Eye-BagKompresse signifikant an, und obwohl bei Verwendung der Augenmaskenkompresse kein signifikanter Unterschied im Lipidschichtgrad und der nicht invasiv gemessenen TBUT bestand, war eine Verbesserung zwischen den Behandlungen zu beobachten. Subjektiv bevorzugten die meisten Probanden Eye-Bag-Kompressen gegenüber Augenmaskenkompressen [120].

In einer Untersuchung, in der die Auswirkungen von TNFastimuliertem Gen/Protein-6 (TSG-6), topischem Prednisolon und topischem Ciclosporin (CsA) auf die Verringerung der DESassoziierten Veränderungen bei NOD-Mäusen verglichen wurden, führten alle drei zu einem Anstieg der Tränenproduktion und der konjunktivalen Becherzellzahl. Außerdem führten 1\%ige Prednisolon-Augentropfen nicht zu einer verminderten Färbung des Hornhautepithels, wohingegen dies unter TSG-6 und CsA $(0,05 \%)$ der Fall war. Ferner kam es bei topischer Verabreichung von TSG-6, Restasis (CsA) und Pred Forte (Prednisolonacetat, 1\%) zu einer signifikanten Abnahme der Transkript-Konzentration von TNF- $\alpha$ und IFN- $\gamma$ an der Augenoberfläche und in den intraorbitalen Drüsen; zudem erhöhte Pred Forte die EpithelzellApoptose und verminderte die Hornhautdicke [121]. Das nichtsteroidale Antirheumatikum Diclofenac verhinderte im Rattenmodell DES-Veränderungen ohne die Menge an Tränenflüssigkeit zu verringern, und es reduzierte die durch Hyperosmolarität induzierte Zellschädigung und Apoptose [122].

CsA ist ein entzündungshemmendes Medikament, das zur Behandlung des Trockenen Auges eingesetzt wird. Aufgrund zahlreicher Nebenwirkungen im Zusammenhang mit der systemischen Verabreichung von CsA sind topische Tropfen die Applikationsart der Wahl für die Behandlung der Augenoberfläche; allerdings stellt die Formulierung eines sicheren Applikationssystems für dieses hydrophobe Medikament eine Herausforderung dar. Die derzeit verfügbaren Präparate von topischem CsA sind häufig mit Nebenwirkungen wie Augenbrennen, Fremdkörpergefühl und Tränenfluss verbunden [123]. Eine 6- und 12-wöchige Behandlung mit einer topischen Augenemulsion von 0,05\%igem CsA zweimal täglich erhöhte jedoch die Dichte an konjunktivalen Becherzellen und der transforming growth factor $\beta 2$-positiven Becherzellen. Dies spricht dafür, dass diese Behandlung die Bildung des immunregulatorischen Faktors TGF- $\beta 2$ durch Erhöhung der konjunktivalen Becherzellen steigert [124]. In einer anderen Studie stellte die Vitamin-B12-Supplementierung das Tränenvolumen und die TBUT im Mausmodell zum Trockenen Auge wieder her, und die einmonatige Behandlung mit Vitamin B12 und 0,15\%iger Hyaluronsäure verringerte den oxidativen Stress und den OSDI [125].

Oxidativer Stress ist an der Pathogenese des Trockenen Auges beteiligt. Eine frühere Studie untersuchte die antioxidative Wirkung von SkQ1, einem synthetischen Antioxidans, zur Prävention des Allgemeinanästhesie-bedingten Trockenen Auges. Es zeigte sich, dass die Prämedikation mit SkQ1 $(7,5 \mu \mathrm{M})$ mit präventiven Effekten gegen pathologische Hornhautveränderungen nach dem Aufwachen verbunden war und die klinischen Symptome des Trockenen Auges bereits ab dem ersten Tag nach der Narkose vollständig aufhob. Die Behandlung nach der Anästhesie erfolgte für eine Woche, wobei diese Ergebnisse eher auf eine protektive Wirkung von SkQ1 auf das Hornhautepithel als auf eine Beteiligung an der Wundheilung der Hornhaut hindeuten. Darüber hinaus erhöhte die Verabreichung von SkQ1 die GPXund Glutathion-Reduktase-Aktivität und beschleunigte die Normalisierung der Konzentration von SOD und anderen Oxidantien in der Tränenflüssigkeit; außerdem erhöhte sie die IL-10-Sekretion, beschleunigte die Erholung der IL-4-Spiegel und bewirkte eine Suppression der TNFa- und IL-6-Sekretion. Darüber hinaus nimmt die MDA-Konzentration bei Tieren, die vor der Anästhesie SkQ1 als Prämedikation erhielten, im Vergleich zu den Kontrolltieren signifikant ab, was dessen antioxidative Wirkung stützt [126]. 
Diquafosol-Tetrasodium (DQS) ist ein purinerger $\mathrm{P}_{2} \mathrm{Y}_{2}$-Agonist, der Berichten zufolge über verschiedene Wirkmechanismen zu einer Verbesserung des Trocken Auges führt, indem er unter anderem den Flüssigkeitstransport verbessert, die Sekretion von Mucin aus dem Bindehautepithel erhöht und die Lipidbildung stimuliert [127]. Ikeda et al. [128] untersuchten den Effekt von 3\%igen DQSAugentropfen auf die funktionellen Veränderungen der MDD bei Sod1 ${ }^{-/-}$-Mäusen und stellten fest, dass die Installation von DQS die Bildung von wässrigen Tränen erhöhte. Ferner zeigten Sod1 ${ }^{-/-}$ Mäuse eine signifikant kürzere TBUT, und eine zweiwöchige Behandlung führte zu einem signifikanten Rückgang der Fluorescein- und der Lissamingrün-Färbung der Hornhaut. Zudem beobachteten sie eine erhöhte Expression von Cytokeratin-4 und IL-13 im azinösen Meibom-Drüsenepithel und verminderte Transglutaminase-1-mRNA- und Proteinkonzentrationen bei Mäusen, die mit DQS behandelt worden waren [128].

Thrombospondin-1 (TSP-1) aktiviert TGF- $\beta$, das eine immunmodulatorische Rolle an der Augenoberfläche spielt [129]. Tan et al. [130] stellten fest, dass die TSP-1-Konzentration in der Hornhaut von DES-Mäusen heraufreguliert ist, und interessanterweise nahm die Expression von MHC II durch vom Knochenmark abgeleitete dendritische Zellen (bone-marrow-derived DCs, BMDCs) nach Co-Kultivierung mit Epithelzellen von DES-Mäusen signifikant ab. Durch weitere Zugabe von rekombinantem (r) TSP-1 wurde der supprimierende Effekt von Epithelzellen auf die BMDC-Reifung verstärkt, während die TSP-1-Blockade diese Wirkung minderte. Außerdem bewirkte TSP-1 einen Rückgang der Th17-Population in den drainierenden Lymphknoten von DES-Mäusen und es verringerte die Zytokinexpression in der Bindehaut und Hornhaut im Vergleich zu den Werten der Kontrollen. Studien ergaben, dass Interaktionen zwischen proinflammatorischen und immunregulatorischen Th17-Zellen eine zentrale Rolle in der Pathogenese des Trockenen Auges spielen [20, 32]. Eine anhaltende Freisetzung von CCL22 aus Mikrosphären, die lokal in die Tränendrüsen injiziert wurden, verhinderte den Rückgang der Tränenproduktion und der Becherzellen und erhöhte die Zahl der CD4-positiven T-Zellen in den regionalen drainierenden Lymphknoten. Außerdem führte sie in Tiermodellen zum Trockenen Auge zu einem Anstieg der CD4+IFN- $\gamma+-\mathrm{T}$ Zellen und verringerte die CD4+Foxp3+-T-Zellen in Tränendrüsen und Hornhäuten [131].

Insgesamt lässt sich sagen, dass die meisten verfügbaren Behandlungsstrategien darauf ausgerichtet sind, die Feuchtigkeit der Augenoberfläche zu erhöhen und die Osmolarität und Entzündung zu verringern. Die Medikamente und Supplementierungen der Zukunft werden den oxidativen Zustand und die metabolische Regulation an der Augenoberfläche verbessern. Diese Herangehensweise sollte in zukünftigen Studien und klinischen Prüfungen berücksichtigt werden. Ein vermutetes Verbindungsglied zwischen oxidativem Stress und Entzündungsreaktion ist beispielsweise der TLR-Signalweg, und dieser wurde in neueren Studien als Angriffspunkt für Supplementierungen vorgeschlagen ein Ansatz, der in zukünftigen Studien zur Entwicklung von DESTherapien untersucht werden könnte [132, 133].

\section{Zukünftige Wege}

Das Ttrockene Auge stellt eine bedeutsame klinische Herausforderung dar. Frühere Untersuchungen stellten fest, dass sich die Zeichen und Symptome des Trockenen Auges unterscheiden [134, 135], was den Bedarf für neue Krankheitsmarker mit einem höheren prädiktiven Wert unterstreicht. Die Identifizierung solcher Marker erfordert oft den Einsatz neuer Messverfahren [80]. In der vorliegenden Übersichtsarbeit wurden die jüngsten Fortschritte in der analytischen Chemie, Mikrobiologie und Biotechnologie sowie ihre jeweilige Anwendung bei der Diagnose und Behandlung des trockenen Auges beleuchtet. Insbesondere haben wir die neu identifizierten immunmetabolischen Mechanismen und mikrobiom-bezogenen Faktoren, die an der Pathogenese des Trockenen Auges beteiligt sind, hervorgehoben. Die neu entdeckten Biomarker lassen hoffen, dass sie die Diagnose und Vorhersage der Krankheit verbessern, doch sind weitere Studien erforderlich, um die Biomarker zu ermitteln, die zur Feststellung des Krankheitsschweregrads am besten geeignet sind. Zunehmend werden von den Augenärzten Modellierungsansätze, die auch maschinelle Lernverfahren und künstliche Intelligenz umfassen, genutzt, und sie können zur Identifizierung klinisch sinnvoller Muster in den Daten herangezogen werden. Darüber hinaus werden Invitro-Krankheitsmodelle, wie beispielsweise das Eye-on-a-Chip, effiziente Screening-Plattformen für die zukünftige Medikamentenentwicklung darstellen.

\section{Danksagungen}

Wir danken Fatemeh Vafaei für ihre Hilfe bei den Grafiken und Tina Shiang für die Hilfe bei den Vorbereitungen im Zusammenhang mit der Erstellung dieses Manuskripts.

\section{Finanzielle Unterstützung}

Diese wissenschaftliche Arbeit wurde nicht durch externe Finanzierung unterstützt.

\section{Interessenkonflikte}

Die Autoren erklären keine Interessenkonflikte.

\section{Literatur}

Die Literatur ist als Supplemental Material unter www.karger.com/?= DOI507467 verfügbar.

\section{Lizenzangabe}

Mostafa Heidari, Farsad Noorizadeh, Kevin Wu, Takenori Inomata, and Alireza Mashaghi: Dry eye disease: emerging approaches to disease analysis and therapy. J Clin Med. 2019;8:pii:E1439 (https://doi.org/10.3390/jcm8091439), (c) 2019 by the authors (Übersetzung), lizensiert unter CC BY 4.0 (https:// creativecommons.org/licenses/by/4.0/deed/de). 